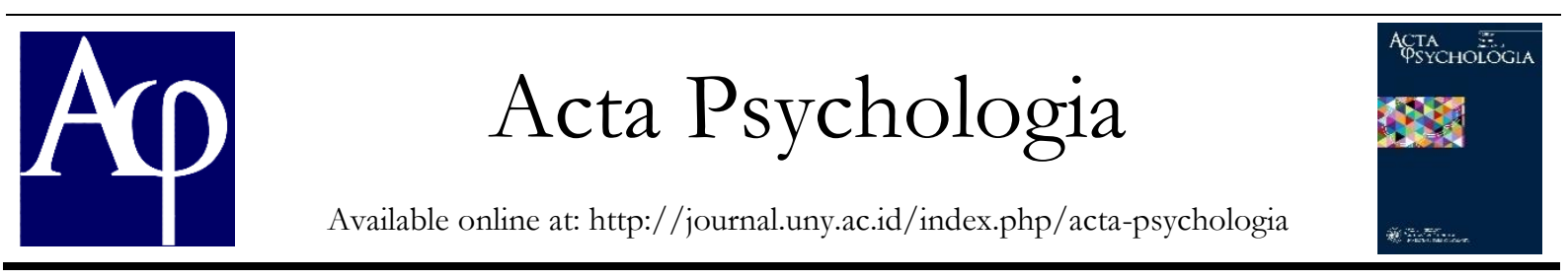

\title{
Makna Hidup Penderita Kanker Payudara Pasca Mastektomi
}

\author{
Diah Dinar Utami \\ Jurusan Psikologi, Fakultas Ilmu Pendidikan, Universitas Negeri Yogyakarta; \\ Jl. Colombo No. 1 Sleman Yogyakarta, 55281 \\ diahdinar31@gmail.com
}

\begin{abstract}
Abstrak
Makna hidup dapat diartikan sebagai sesuatu yang muncul dari dalam diri sebagai arah tujuan dalam hidup untuk menemukan suatu istilah yang dianggap bermakna. Penelitian ini bertujuan untuk menemukan bagaimana dinamika makna hidup pada penderita kanker payudara pasca mastektomi dan apa saja faktor-faktor yang memengaruhi makna hidup para penderita kanker payudara pasca mastektomi. Penelitian ini menggunakan metode kualitatif dengan pendekatan fenomenologis. Sebanyak lima responden terlibat dan diwawancarai secara mendalam. Analisis dari transkrip wawancara menggunakan Interpretative Phenomenological Analysis (IPA) agar dapat mengetahui esensi dinamika makna hidup dan juga faktor-faktornya yang ada pada orang yang mengalami kanker payudara dan sudah di mastektomi. Penelitian ini menunjukkan adanya perubahan makna hidup pada penderita kanker. Sebelum didiagnosis kanker, para subjek memaknai hidupnya sebagai pribadi yang dapat memberikan kasih sayang terhadap keluarga dan berubah menjadi pribadi yang bersyukur dengan keadaan dirinya saat sakit dan ingin menjalani hidup lebih bermanfaat untuk lingkungan sekitar. Adanya perubahan makna hidup ini di pengaruhi oleh 7 faktor yang ditemukan dalam penelitian ini. Faktor-faktor yang memengaruhi makna hidup pada penderita kanker pasca mastektomi yaitu self insight, self commitment, spiritualitas, dukungan sosial, harapan, kebersyukuran, dan mindfulness.
\end{abstract}

Kata kunci: Makna hidup, penderita kanker payudara pasca mastektomi, fenomenologis

\begin{abstract}
Meaning in life can be interpreted as something that rises within the self as purpose of life to find a verbalization that is considered meaningful. This study aims to figure out the dynamics of meaning in life on post-mastectomy breast cancer patients and the contributing factors to meaning in life on post-mastectomy breast cancer patients. This study uses a qualitative method and phenomenological approach. In depth interviews have been carried out to five respondents. The interview transcripts then analyzed using Interpretative Phenomenological Analyzes (IPA) thus the essence of meaning in life dynamics can be figured out, as well as the contributing factors related to postmastectomy breast cancer patients. This study found a change upon meaning in life on post-mastectomy breast cancer patients. Before diagnosed with cancer, the patients place a meaning in their life as an individual who is capable of providing love to their family but then changed into an individual who is grateful with their health condition and wanting to live a life that is useful for their surroundings. This change in meaning in life caused by seven factors found in this study. The contributing factors found are self-insight, self-commitment, spiritualism, social support, hope, gratefulness, and mindfulness.
\end{abstract}

Keywords: meaning in life, post-mastectomy breast cancer patients, phenomenology

\section{Pendahuluan}

Kanker payudara merupakan problem kesehatan yang sangat serius karena jumlah yang semakin meningkat $(20 \%)$ per tahun dan merupakan penyebab kematian nomor dua setelah kanker leher rahim (WHO, 2015).. Kanker payudara menduduki peringkat pertama kasus kanker pada wanita di seluruh dunia dengan angka kejadian sebesar 1.676.633 dan kanker hati menduduki peringkat tiga dunia dengan angka 879.987 kasus didunia. Kanker 
payudara merupakan penyebab kematian akibat kanker yang paling banyak pada wanita (IARC, 2015). Kanker payudara sering ditemukan di negara- negara besar dengan insiden relatif tinggi, yaitu 20\% dari seluruh keganasan kanker yang ada. Dari 600.000 kasus kanker payudara yang didiagnosis setiap bulan sebanyak 350.000 diantaranya ditemukan di negara maju, sedangkan 250.000 di negara berkembang (WHO, 2015).

Kanker dapat menantang pengalaman pencarian makna hidup. Diagnosis dan konsekuensi dari penyakit yang mengancam jiwa seperti kanker dapat menghancurkan persepsi diri, sikap hidup, asumsi individu, dan sistem nilai (Habermas \& Bluck, 2000). Beberapa orang yang dihadapkan dengan diagnosis dan pengobatan kanker mungkin terpaksa mengubah pandangan hidup mereka karena hal itu tidak lagi memberikan arah yang cukup untuk hidup. Ancaman terhadap kehidupan dapat menantang keyakinan orang tentang kehidupan dan rasa sejahtera mereka. Pasien kanker payudara yang memiliki makna dalam hidupnya menunjukkan fungsi fisik dan psikologis yang lebih baik pada penilaian tindak lanjut 4 bulan setelah akhir pengobatan (Sherman dkk., 2010). Selain itu, pasien yang mempunyai makna hidup memiliki stress yang rendah dan kesejahteraan yang lebih baik (Park dkk., 2008). Penelitian lain menemukan pencarian akan makna hidup berhubungan positif dengan keterbukaan dan keingintahuan pasien terhadap penyakitnya (Steger dkk., 2008).

Makna hidup seseorang dapat ditemui melalui berbagai macam pengalaman kehidupan baik itu yang negatif maupun pengalaman yang positif. Makna hidup dapat diartikan sebagai sesuatu yang muncul dari dalam diri sebagai arah tujuan dalam hidup untuk menemukan suatu istilah yang dianggap bermakna. Kebermaknaan dicapai oleh masing-masing individu terkait dengan apa yang sudah ia capai dan ia jalani dalam hidupnya. Selain itu, di dalam makna hidup juga terdapat komitmen yang lebih besar dari diri sendiri dan makna itu dapat di hadirkan dari peristiwa yang membahagiakan dan juga peristiwa yang kurang di inginkan dalam hidup.

Menurut Bastaman (2007) makna hidup adalah berbagai hal yang dipandang penting, dirasakan berharga, diyakini oleh manusia sebagai sesuatu yang benar dan dapat dijadikan tujuan hidupnya. Selanjutnya Frankl (1984) berpendapat bahwa kebermaknaan hidup individual manusia senantiasa terkait dengan kualitas penghayatan tentang tujuan hidupnya. Penghayatan ini menyebabkan adanya peningkatan batin dalam dirinya, karena mencapai kehidupan yang bermakna itu membutuhkan perjuangan yang tidak kenal lelah.

\section{Metode Penelitian}

Penelitian kualitatif ini akan di lakukan dengan fenomenologi. Fenomenologi dipilih untuk memahami fenomena tentang apa yang dialami oleh subjek penelitian (misal: perilaku, persepsi, motivasi, dan mood) secara holistik dan dengan cara deskripsi dalam bentuk katakata dan bahasa pada suatu konteks khusus yang alamiah (Moleong, 2016). Tempat dan waktu penelitian akandilakukan di kediaman subjek yang berdomisilidi Daerah Istimewa Yogyakarta dan Jakarta.

Responden dalam penelitian ini dipilih menggunakan teknik purposive, yakni responden tidak diambil secara acak, namun berdasarkan kriteria-kriteria tertentu sesuai dengan tujuan penelitian sehingga responden dapat benar-benar mewakili fenomena yang diteliti (Herdiansyah, 2015). Penetuan responden dalam penelitian ini, berdasarkan kriteriakriteria berikut :

1. Penderita kanker payudara yang sudahdi masektomi

2. Jenis kelamin wanita

3. Berusia $30-60$ tahun

4. Bersedia menjadi responden dalam penelitian ini. 
Prosedur analisis data dan interpretasi pada penelitian ini menggunakan Interpretative Phenomenological Analysis (IPA). Interpretative Phenomenological Analysis (IPA) adalah pendekatan kualitatif yang bertujuan untuk memberikan pemeriksaan rinci terhadap pengalaman hidup subjek yang diteliti (Smith, Flowers, \& Larkin 2009). Interpretative Phenomenological Analysis adalah metodologi yang sangat berguna untuk meneliti tema penelitian yang memiliki topik kompleks, ambigu, dan bermuatan emosional. memeriksa rasa sakit. Terdapat enam langkah dalam analisis data menggunakan IPA (Smith, Flowers, dan Larkin, 2009), yakni: (1) reading and re-reading, (2) initial noting, (3) developing emergent themes, (4) searching for connection across emergent themes, (5) moving to the next case, (6) looking for patterns across cases.

\section{Hasil Penelitian dan Pembahasan}

Peneliti menggunakan 5 subjek yang berkenan untuk berpartisipasi dalam penelitian ini. Kelima subjek ini yaitu PR, MU, MR, RN, dan AR. Subjek-subjek ini memiliki latar belakang penyakit yang berbeda-beda dengan status stadium kanker yang berbeda-beda. Selain mengambil data dari kelima subjek tersebut, peneliti juga mengambil data dari 2 significant others. Hasil penelitian ini didapatkan dari wawancara mendalam dan juga observasi terhadap para subjek dan significant others. Berikut hasil pemaparan ringkasan dari hasil wawancara dan observasi.

Pembahasan

Koneksi antara makna dalam kehidupan, persepsi penyakit, dan perubahan makna dapat lebih dipahami dalam meaning making models, yang telah berhasil diterapkan dalam bidang kesehatan (Park, 2013). Model ini berpendapat bahwa individu memiliki sistem yang berorientasi yang memberi mereka kerangka kerja kognitif yang memungkinkan mereka untuk menafsirkan pengalaman mereka dengan adanya motivasi yang memperkuat sumber daya diri. Ketika orang menghadapi situasi yang penuh tekanan (misal: kanker payudara), mereka menilai situasi dan memberi makna pada situasi yang mereka rasakan.

Persepsi individu tentang perbedaan antara makna mereka yang dinilai dari situasi tertentu dan makna global, menghasilkan adanya makna baru dalam hidupnya (Park, 2013). Makna mewakili proses di mana orang terlibat untuk mengurangi perbedaan antara makna sebelum sakit dan setelahnya. Prosesnya melibatkan: (1) mengubah makna yang dinilai situasional atau keyakinan dan tujuan global, (2) mencari pemahaman yang lebih baik tentang situasi dan implikasinya, dan (3) mempertimbangkan kembali kepercayaan global dan merevisi makna hidup seseorang. Semua proses dapat terjadi dalam konteks penyakit serius dan mengarah pada konsekuensi positif atau negatif untuk penyesuaian mental.

\section{1) Mengubah makna yang dinilai situasional atau keyakinan dan tujuan global}

Sebelum didiagnosis memiliki kanker payudara, kehidupan 5 subjek hanya berkutat dengan kesehariannya sebagai pedagang, guru, maupun ibu rumah tangga. Permasalahan yang ia hadapi hanya seputar hal tersebut. Mereka memaknai kehidupannya sebagai sarana untuk mengejar rezeki, memenuhi kebutuhan hidup dalam rumah tangga, mendidik anak agar tumbuh sebagai pribadi yang baik. Memaknai kehidupan tidak melulu mengenai pemaknaan yang bersifat kompleks dan juga bersifat filosofis. Memaknai kehidupan dapat berupa pengalaman sehari-hari. Setiap kontrol, subjek akan menemui pasien lainnya dengan kondisi berbeda-beda yang dapat membuat subjek lebih memaknai akan kesehatan. Memahami dirinya dan penyakitnya merupakan salah satu faktor yang membuat ia dapat memaknai sakit ini sebagai makna 
hidupnya yang baru. Melihat kondisi diri dan membandingkan dengan orang lain pun memiliki dampak yang positif untuk meyakinkan diri dengan kondisi yang sekarang atau negatif untuk penyesuaian mental.

\section{2) Mengubah makna yang dinilai situasional atau keyakinan dan tujuan global}

Sebelum didiagnosis memiliki kanker payudara, kehidupan 5 subjek hanya berkutat dengan kesehariannya sebagai pedagang, guru, maupun ibu rumah tangga. Permasalahan yang ia hadapi hanya seputar hal tersebut. Mereka memaknai kehidupannya sebagai sarana untuk mengejar rezeki, memenuhi kebutuhan hidup dalam rumah tangga, mendidik anak agar tumbuh sebagai pribadi yang baik. Memaknai kehidupan tidak melulu mengenai pemaknaan yang bersifat kompleks dan juga bersifat filosofis. Memaknai kehidupan dapat berupa hal-hal yang berkaitan dengan pengalaman ataupun kebiasaan sehari-hari yang di lakukan oleh manusia.

Setelah didiagnosis kanker, kehidupan subjek pun berubah dan harus berkutat dengan obat-obatan, perawatan rumah sakit, dan juga kemoterapi. Banyak hal-hal baru yang di pelajari oleh subjek dari kesehariannya selama menjalani pemulihan kanker. Setiap kontrol, subjek akan menemui pasien lainnya dengan kondisi berbeda-beda yang dapat membuat subjek lebih memaknai akan kesehatan. Memahami dirinya dan penyakitnya merupakan salah satu faktor yang membuat ia dapat memaknai perjalanan sakit ini sebagai makna hidupnya yang baru. Melihat kondisi diri dan membandingkan dengan orang lain pun memiliki dampak yang positif untuk meyakinkan diri dengan kondisi yang sekarang.

\section{3) Mencari pemahaman yang lebih baik tentang situasi dan implikasinya}

Manusia memiliki keinginan untuk memiliki hidup yang berarti dan bermakna.
Frankl (1984) mendefinisikan makna sebagai manifestasi nilai berdasarkan kreativitas, pengalaman, dan sikap. Frankl (1984) mengatakan pada salah satu pernyataannya yang terkenal bahwa manusia dapat mengatasi setiap penderitaan jika mereka dapat menemukan makna di dalamnya. Ini sangat relevan dengan perawatan kesehatan, terutama yang berkaitan dengan pasien yang menderita penyakit parah seperti menderita kanker. Adanya kebermaknaan dalam pengalaman kanker yang di derita oleh subjek membuat subjek lebih mampu menjalani hari-hari dengan kuat.

Makna hidup dapat di lihat sebagai satu set keterampilan kognitif, seperti membuat atribusi tujuan dan makna dan menemukan intensionalitas di dalam kehidupan pribadi. Ada bukti empiris bahwa makna dalam hidup memainkan peran penting pada pasien kanker (Park, 2013; Winger, Adams, \& Mosher, 2016). Hal ini menyoroti fakta bahwa individu memiliki arti makna dalam hidup ketika mereka diyakinkan tentang makna dan tujuan hidup mereka sendiri. Hal ini pun dirasakan oleh PR, ia tidak pernah merasa bosan untuk kontrol ke rumah sakit karena selalu bahagia apabila mendengar hasil kontrol dari dokter bahwa penyakitnya semakin membaik. Ketika ia mendengar bahwa penyakitnya bertambah baik, hal ini ia maknai untuk menjaga kesehatannya agar cepat pulih. Selain itu, RN pun demikian, melihat kondisi diri saat sakit dan tujuan hidupnya kala itu, ia yakin dan terus menjalani kemoterapi hingga selesai

\section{4) Mempertimbangkan kembali kepercayaan global dan merevisi makna hidup seseorang \\ Memaknai hidup setelah 'sembuh' dari penyakitnya, para subjek terkadang memiliki perbedaan dalam pola pikirnya. Kehidupan yang sekarang di anggap sebagai kehidupan kedua untuk memulai hal-hal yang lebih baik lagi dari kehidupan sebelumnya. Perbedaan memaknai hidup juga dikarenakan adanya pembelajaran baru.}


Belajar melalui pengalaman sakit membuat subjek memiliki pola pikir dan pola hidup yang lebih baik. Mereka memiliki cita-cita untuk dapat lebih bermanfaat untuk orang lain di sisa hidupnya

Dari proses ini, menunjukkan bahwa ketika orang-orang dengan kanker yang sudah memiliki makna, mereka memiliki dasar yang kuat yang memungkinkan mereka untuk melihat penyakit mereka secara lebih positif dan mengalami lebih sedikit efek yang merugikan dalam kepercayaan drinya dan sistem tujuan hidupnya. Sebaliknya, ketika pasien belum mencapai tingkat makna yang memuaskan dalam hidup, pencarian mereka akan makna atau ketiadaannya bisa menjadi masalah dan membuat frustrasi, yang menghasilkan citra penyakit yang lebih negatif.

Selain itu, hasil dari penelitian ini memberikan bukti yang mendukung untuk menunjukkan bahwa emosi positif memainkan peran yang penting dalam proses pembuatan makna. Dalam penelitian yang di lakukan oleh Frederickson (2001) menemukan bahwa, pengaruh emosi positif dapat memfasilitasi perluasan perhatian, kognisi, dan tindakan seseorang. Pada penderita kanker ada kemungkinan bahwa melalui proses kognitif ini, pengaruh positif dapat membantu membangun sumber daya diri yang dapat membuat hidup lebih bermakna. Dengan kata lain, ada kemungkinan bahwa emosi positif memfasilitasi makna dengan membuat seseorang lebih mungkin untuk waspada terhadap apa yang mungkin berharga atau bermakna, merasa lebih terdorong untuk mengejar tujuan yang berharga yang dapat membantu merasa bahwa kehidupan memiliki tujuan, dan lebih mampu mengintegrasikan informasi untuk memahami kehidupannya yang sekarang.

\section{Faktor-faktor makna bidup}

Pemaknaan dalam hidup melalui proses perubahannya pun di dukung dengan faktor- faktor lainnya. Faktor-faktor yang mendukung dalam pemaknaan hidup para subjek meliputi 7 faktor yang di dapatkan dari hasil wawancara subjek. Berikut pemaparan rinci mengenai ketujuh faktor tersebut:

\section{a. Self insight}

Memahami kondisi diri dengan adanya sel CA yang akan selalu menemani hingga akhir hayat, merupakan hal positif yang dapat membantu para subjek memaknai hidupnya dengan pola pikir yang lebih baik. Selain itu, untuk subjek yang masih dalam proses kemoterapi, adanya self insight membantu dirinya untuk kuat dalam menjalani pengobatan dan mengarahkan pola pikir untuk menerima keadaannya yang sekarang.

Selain itu, menjadi survivor kanker juga membutuhkan adanya kesadaran dengan kondisinya yang sekarang. Adanya self-insight membantu survivor untuk menjaga pola makan dan pola hidupnya agar tidak terjadi metastasis.

\section{b. Self-Commitment}

Komitmen adalah sesuatu yang mengikat individu untuk melakukan sesuatu yang sesuai dengan sasaran atau tujuan yang ingin di tuju. Adanya komitmen diri pada individu membuat ia dapat mematangkan tekad untuk mencapai sesuatu yang menjadi tujuan sekalipun individu tersebut belum mengetahui bagaimana hasil akhirnya. Komitmen pada diri juga merupakan langkah yang di ambil untuk memulai suatu tindakan tertentu yang sudah diniatkan sepenuh hati. Pada warrior dan survivor kanker, mereka memiliki komitmen masingmasing untuk mencapai tujuannya masingmasing. Tiap subjek memiliki komitmen yang hampir sama yaitu menjaga dirinya untuk tetap sehat agar bisa hidup berdampingan dengan sel CA. Komitmen para subjek pun tercermin dari bagaimana mereka patuh dengan saran dokter dan mengikuti anjuran yang di berikan oleh dokter yang menanganinya. Komitmen untuk sembuh dan memahami kondisi dirinya menjadi motivasi besar untuk menjalani perawatan kanker. 


\section{c) Spiritualitas}

Spiritualitas sering kali berperan besar dalam upaya individu untuk menghadapi penyakit serius (Cummings \& Pargament, 2010; Koenig dkk., 2012). Para subjek yang memiliki kepercayaan agama yang lebih tinggi memiliki rasa kemanjuran yang lebih tinggi dalam mengatasi kanker mereka, yang memperkirakan penyesuaian yang lebih baik dan menemukan makna dengan lebih mudah (Howsepian \& Merluzzi, 2009). Spiritualitas yang dimiliki para subjek berkaitan dengan adanya keyakinan bahwa tuhan memiliki andil dalam hidupnya. Dengan adanya penyakit ini, bukan di maksudkan tuhan membenci dirinya, namun para subjek mengartikannya sebagai sebuah kado ataupun anugrah yang diberikan oleh tuhan untuk para warrior dan survivor. Mereka merasakan bahwa dengan adanya penyakit ini, mereka menjadi lebih dekat dengan tuhan dan membuat para subjek dapat dengan cepat menguatkan hati dan pikirannya untuk memilih makna hidupnya yang baru.

Andil tuhan yang membuat para warrior kuat menjalani semua perawatan dan perjalanan kemoterapi yang sedang dilaluinya sekarang. Selain itu dalam hidup survivor, adanya spiritualitas dalam dirinya juga yang membuat ia mampu bertindak secara positif dalam menjalani hari-hari setelah di nyatakan 'sembuh'. Pada akhirnya, makna yang dibuat dapat berupa perubahan dalam penilaian spiritual dari penyakit seseorang, seperti melihat kondisi yang sekarang sebagai kesempatan untuk tumbuh lebih dekat dengan Tuhan atau menjadi lebih berbelas kasih pada orang lain dan sabar dengan kehidupan. Makna yang dibuat juga dapat melibatkan transformasi spiritual dari keyakinan dan tujuan seseorang. Para subjek pun melaporkan merasa lebih dekat dengan tuhan, lebih yakin dengan iman mereka, dan lebih berkomitmen pada agama mereka. Banyak juga melaporkan berperilaku lebih belas kasih dan menemukan makna spiritual lebih dalam hubungan mereka dengan orang lain dan diri mereka sendiri (Cole dkk., 2008).

\section{d) Dukungan sosial}

Berbagai faktor kontekstual, termasuk lingkungan sosial, menentukan kesehatan dan kesejahteraan. Lingkungan sosial terdiri dari hubungan interpersonal dalam keluarga seseorang, kelompok sebaya, pekerjaan, lingkungan, organisasi agama, dan kelompok pendukung (Schmidt \& Andrykowski, 2004). Hubungan antara lingkungan sosial dan kesehatan telah dibentuk sebelum subjek terkena kanker. Namun, arah hubungan itu bervariasi tergantung pada apakah lingkungan sosial menawarkan dukungan atau penolakan (Remmers, Holtgrawe, dan Pinkert, 2010). $\mathrm{Hal}$ ini pun terlihat dari proses penerimaan diri dengan kanker yang dimiliki oleh para subjek. Ketika keluarga mendukung dengan perawatan kanker yang mereka jalani, subjek pun merasa bahwa dirinya masih di terima dan menjadi motivasi bagi subjek untuk sembuh.

Memiliki dukungan sosial terkait dengan kualitas hidup yang lebih tinggi (Helgeson, 2003). Memahami lingkungan sosial pasien dapat mengungkapkan proses penanggulangan kanker yang mereka miliki (Dunn dkk., 2011; Knott dkk., 2012). Pasien kanker yang terhubung dengan baik ke lingkungan sosial mereka memiliki ketahanan yang lebih baik (Denz-Penhey \& Murdoch, 2008). Ketika adanya dukungan yang diberikan oleh lingkungan sekitar, subjek secara tidak langsung meningkatkan optimisme dirinya untuk segera sembuh dan kembali melakukan aktivitas sehariharinya. Para subjek juga memandang penyakit yang dimilikinya bukan sebagai hambatan untuk mengembangkan potensi yang dimilikinya seperi hobi yang para subjek tekuni.

Beberapa penelitian menunjukkan hubungan positif antara dukungan sosial dan hasil kesehatan klinis, seperti kepatuhan minum obat dan mortalitas (Beasley dkk., 2010; Kroenke dkk., 2017). Penelitian ini sejalan dengan hasil temuan para subjek 
yang mendapat banyak dukungan dari keluarga untuk meminum obat secara teratur dan tetap melakukan kemoterapi. Dengan adanya dukungan seperti itu, subjek merasa bahwa semangatnya berkobar kembali karena merasa masih ada yang peduli pada dirinya.

Untuk wanita yang sedang mengalami sedang terapi adjuvant untuk kanker, kebutuhan dukungan sosial yang tidak terpenuhi juga dikaitkan dengan peningkatan beban gejala pro-inflamasi leukosit (Kroenke dkk, 2017), pro-inflamasi yang lebih tinggi pada ekspresi gen metastatik (Jutagir dkk., 2017), peningkatan gejala depresi (Hughes dkk., 2014), dan kualitas hidup keseluruhan yang lebih rendah (Leung, Pachana, \& McLaughlin, 2017). Hal ini juga terjadi pada MU, ia mengalami adanya kekurangan leukosit di karenakan banyaknya pikiran mengenai kondisi dirinya pada awal diagnosis kanker.

Dukungan yang di berikan oleh para penderita kanker lainnya dengan berbagi cerita dan pengalaman kanker, membuat subjek dapat meningkatkan optimisme dirinya untuk sembuh dan kuat menjalani hari-hari selama menderita kanker. Hal ini juga terlihat dari 5 subjek yang diteliti. Dukungan sosial dari teman dan keluarga serta dukungan pengalaman dari penderita kanker payudara lainnya diperlukan untuk membantu para subjek mengarahkan perawatan tambahan mereka seperti meminum obat-obatan peningkat imunitas, memakan makanan- makanan tertentu untuk mengeringkan luka, dsb.

Adanya dukungan dari sesama penderita membuat mereka yakin untuk sembuh (Karakoyun-Celik dkk., 2010). Untuk pasien kanker payudara, peningkatan kontak dengan teman-teman survivor kanker dikaitkan dengan peningkatan kualitas hidup (Karakoyun-Celik dkk., 2010) dan dengan risiko kematian yang lebih rendah (Chou dkk., 2012). Menghabiskan waktu dengan teman-teman survivor juga dapat mengakibatkan peningkatan keterampilan mengatasi keluhan yang ia rasakan, menerima dukungan emosional dan instrumental tambahan, dan meningkatkan peluang untuk berbagi informasi kesehatan (Chou dkk., 2012).

\section{d. Harapan}

Harapan sebagai salah satu elemen terpenting dalam kehidupan pasien yang berjuang dengan diagnosis kanker. Harapan membantu mereka mengatasi kesulitan dan ketidakpastian diagnosis mereka (Hammer \& Morgenson, 2009). Harapan pasien onkologi tampaknya terkait dengan berbagai faktor, baik fisik (misalnya, tingkat nyeri dan energi) dan psikologis (misalnya, kecemasan dan depresi). Harapan yang dimiliki oleh para subjek membawa mereka pada keinginan untuk sembuh. Harapan merupakan salah satu faktor yang dapat membuat seseorang menemukan makna hidupnya (Botor, 2015).

Harapan pada pasien kanker pun membawa mereka untuk tetap menjalani perawatan hingga sembuh. Harapan yang dimiliki juga membuat pasien lebih semangat dalam menjalani perawatan dan menilai kehidupannya menjadi lebih positif. Dalam penelitian ini, para subjek berharap akan kesembuhan dan juga umur yang panjang untuk dapat memenuhi keinginan dan tujuan dalam hidupnya, yaitu membuat keluarga merasa senang dengan hadirnya dalam tumbuh kembang anak-anak subjek. Harapan yang di tujukan untuk keluarga juga biasanya memengaruhi kemampuan pasien kanker untuk mencari makna dalam kondisinya yang sekarang dan menyesuaikan diri dengan kehidupan yang dijalaninya (Hassakhani dkk., 2017).

\section{e. Kebersyukuran}

Syukur merupakan salah satu bentuk dari ekspresi kebahagiaan yang erat kaitannya dengan kesejahteraan. Kebersyukuran pada individu tidak hanya reaksi ketika mendapatkan hal-hal baik dan menyenangkan maupun yang diinginkan, namun bersyukur setiap saat dan mampu 
menghadapi situasi yang tidak menyenangkan, yang mana individu juga akan mampu menghargai setiap apa yang didapatkan di dalam kehidupan (Chintya, 2016). Rasa syukur juga di rasakan MU karena ia merasa bahwa tuhan masih menyayanginya dengan memberikannya cobaan dengan penyakit kanker.

Bersyukur dapat membantu seseorang menikmati pengalaman hidup yang positif sehingga individu mampu meraih kemungkinan terbesar dari kepuasan dan kegembiraan dari situasi yang ia lalui (Lyubomirsky \& Kristin, 2013). Walaupun dengan adanya kanker dalam hidupnya, MR juga merasa bersyukur dengan kondisi dirinya yang masih kuat dan dapat melakukan segala hal secara mandiri dari pengurusan berkas hingga konsultasi check up setiap bulan dengan dokter. Ia merasa ada kebahagiaan dalam dirinya karena masih dapat melakukannya sendiri tanpa bantuan orang lain. Bersyukur menjadikan sesorang merasa bahagia, optimis, dan merasakan kenikmatan dan merima dirinya apa adanya (Froh dkk., 2010). Hal ini juga dirasakan oleh PR, selama ia menjalani sakit ia selalu di berikan kemudahan oleh tuhan untuk menjalaninya. Tindakan bersyukur akan mampu mendorong seseorang untuk dapat menerima dengan ikhlas segala sesuatu yang terjadi dalam kehidupannya. Seperti pada yang terjadi pada para subjek (PR,MU,MR,RN,AR) adanya kebersyukuran membuat mereka lebih bersikap positif dengan kanker yang dideritanya. Bersyukur dapat membuat seseorang tersentuh dalam aspek kognisi (cara berpikir), emosi (berempati), serta spiritual (keyakinan). Dengan adanya kebersyukuran, subjek pun dapat memandang dan memaknai kehidupannya dengan lebih mudah. Dalam hal ini yang dimaksudkan adalah adanya manfaat positif yang didapatkan oleh individu ketika bersyukur, seperti individu akan lebih baik dalam merespon atau menyikapi setiap peristiwa dalam kehidupannya (Cahyono, 2014).

\section{f. Mindfulness}

Penderita kanker sering mengalami kehilangan kendali dan perasaan tidak berdaya. Mindfulness menyediakan tempat perhatian internal, memberdayakan mereka untuk mengambil sikap proaktif dengan secara sadar untuk mengarahkan perhatian mereka pada pengalaman saat ini. Mindfulness adalah kemampuan atau praktik mempertahankan pemikiran untuk tidak menghakimi situasi dalam kehidupan. Penelitian sebelumnya sebelumnya telah menemukan bahwa tingkat mindfulness yang tinggi pada pasien kronis dikaitkan dengan rasa sakit yang dilaporkan lebih rendah (Omidi dan Zargar, 2014; Delgado dkk., 2014; Curtis, Osadchuk, dan Katz, 2011) dan persepsi penanganan rasa sakit yang lebih baik (Gotink dkk., 2015; de Boer dkk., 2014; Dowd dkk., 2015).

Mindfulness yang di rasakan oleh para survivor menjadikan pribadi mereka tidak gampang stres dengan keadaan kehidupannya. Mereka menjalani kehidupan yang berjalan sekarang tanpa merisaukan masa depan dan juga tanpa mengingat masa-masa kelam dengan perawatan kanker yang terkadang membuat dirinya khawatir secara berlebihan. Mindfulness juga di terapkan dalam kehidupan para warrior. Dengan adanya kondisi yang baru dalam hidupnya ia memaknainya dengan menjalaninya tanpa berkeluh kesah dan tidak putus asa dalam pengobatan yang ia jalani

\section{Daftar Pustaka}

Bastaman, H.D. (2007). Logoterapi :Psikologi Untuk. Menemukan Makna Hidup dan Meraih Hidup Bermakna. Jakarta: PT. RajaGrafindo.

Beasley JM, Newcomb PA, TrenthamDietz A, Hampton JM, Ceballos RM, Titus-Ernstoff L, dkk,. (2010). 
Social networks and survival after breast cancer diagnosis. I Cancer Surviv.4:372-380.

Botor, N. (2015). Hope and meaning in life as predictors of depression in a group of selected filipino adolescents, Di akses pada 14 Februari 2019 https://www.researchgate.net/pub lication/281372377

Cahyono, W. E. (2014). Pelatihan gratitude (bersyukur) untuk penurunan stres kerja karyawan di pt. X. Calyptra. Jurnal Ilmiah Mahasiswa Universitas Surabaya, 3, 1-15.

Chintya, D. (2016). Hubungan antara gratitude dengan psychological well being pada mabasiswa UKSW yang kuliah sambil bekerja full time. Tugas Akhir. Salatiga: Universitas Kristen Satya Wacana. Di akses pada 16 Februari 2019

Chou, A. F., Stewart, S. L., Wild, R. C., \& Bloom, J. R. (2012). Social support and survival in young women with breast carcinoma. Psycho-Oncology, 21, 125-133.

Cole, Brenda. S., Clare M.Hopkins , John Tisak, Jennifer L. Steel, Brian I. Carr. (2008). Assessing spiritual growth and spiritual decline following a diagnosis of cancer: reliability and validity of the spiritual transformation scale. Psycho-oncology. 17: 112-121

Cummings, J. P. \& Pargament, Kenneth I. (2010). Medicine for the spirit: religious coping in individuals with medical conditions. Religions, 1, 2853.

Curtis K,. Osadchuk A,. \& Katz J. (2011). An eight-week yoga intervention is associated with improvements in pain, psychological functioning and mindfulness, and changes in cortisol levels in women with fibromyalgia. J Pain Res. 4:189-20

de Boer MJ, Steinhagen HE, Versteegen GJ, Struys MM, Sanderman R. (2014). Mindfulness, acceptance and catastrophizing in chronic pain. PLoS One. 9: 1-6

Delgado R, York A, Lee C, Crawford C, Buckenmaier 3rd C, Schoomaker E, dkk. (2014). Assessing the quality, efficacy, and effectiveness of the current evidence base of active selfcare complementary and integrative medicine therapies for the management of chroni

Denz-Penhey, H., Murdoch, C. (2008). Personal resiliency: serious diagnosis and prognosis with unexpected quality outcomes. Qual Health Res. 18: 391-404.

Dowd H, Hogan MJ, McGuire BE, Davis MC, Sarma KM, Fish RA, dkk, (2015). Comparison of an online mindfulness-based cognitive therapy intervention with online pain management psychoeducation: a randomized controlled study. Clin J Pain. 6: 517-527.

Dunn J, Steginga SK, Rosoman N, Millichap D. (2003). A review of peer support in the context of cancer. J Psychosoc Oncol. 21: 55-67.

Frankl, V.E. (1984). Man's Search for Meaning: An Introduction to Logotherapy. New York: Souvenir Press

Frederickson, B. L. (2001). The role of positive emotions in positive psychology: The broaden-andbuild theory of positive emotions. American Psychologist, 56, 218-226.

Froh, J.J., Bono, G., \& Emmons, R.A. 
(2010). Being grateful id beyond good manners: gratitude and motivation to contribute to society among early adolescents. Motivation Emotion, 34, 144-157.

Gotink RA, Chu P, Busschbach JJ, Benson $\mathrm{H}$, Fricchione GL, Hunink MG. (2015). Standardised mindfulnessbased interventions in healthcare: an overview of systematic reviews and metaanalyses of rets. Plos one. 10: $1-17$

Habermas, T. \& Bluck, S. (2000). Getting a life:The Emergence of the life story in adolenscence. Psychological Bulletin, 126, 748-769.

Hammer, K., Mogensen, O., Hall, E.O. (2009). The meaning of hope in nursing research: a meta-synthesis. Scand J Caring Sci. 3: 549-557.

Hassankhani, H., Firooz, Hasanzadeh., Kelly, A., Abbas, D. Z., Rouzbeh. R. (2017). Clinical skills performed by iranian emergency nurses: perceived competency levels and attitudes toward expanding professional roles. Journal of Emergency Nursing. 44: 156-163

Helgeson, V.S. (2003). Social support and quality of life. Quality of Life Research, 12, 25-31.

Herdiansyah, H. (2015). Metode Penelitian Kualitatif untuk. Ilmu Psikologi. Jakarta: Salemba Humanika.

Howsepian B. A., Merluzzi T. V. (2009). Religious beliefs, social support, self- efficacy and adjustment to cancer. Psychooncology. 18: 1069-1079.

Hughes S, Jaremka LM, Alfano CM, Glaser R, Povoski SP, Lipari AM, dkk, (2014). Social support predicts inflammation, pain, and depressive symptoms: longitudinal relationships among breast cancer survivors. Psychoneuroendocrinology. 42: $38-44$

Jutagir DR, Blomberg BB, Carver CS, Lechner SC, Timpano KR, Bouchard LC, dkk,. (2017). Social well-being is associated with less pro-inflammatory and prometastatic leukocyte gene expression in women after surgery for breast cancer. Breast Cancer Res Treat. 165:169-180.

Karakoyun-Celik, O., Gorken, I., Sahin, S., Orcin, E., Alanyali, H., \& Kinay, M. (2010). Depression and anxiety levels in woman under follow-up for breast cancer: Relationship to coping with cancer and quality of life. Medical Oncology, 27, 108-113.

Knott, Vikki., Deborah, Turnbull., Ian, Olver., Anthony. Winefield. (2012). A grounded theory approach to understand the cancer-coping process. Health Psychology. 17: 551564.

Koenig HG. (2012). Religion, spirituality, and health: the research and clinical implications. ISRN Psychiatry. 16: 38-52.

Kroenke CH, Michael YL, Poole EM, Kwan ML, Nechuta S, Leas E, dkk,. (2017). Postdiagnosis social networks and breast cancer mortality in the After Breast Cancer Pooling Project. Cancer. 123: 12281237.

Leung J, Pachana NA, McLaughlin D. (2014). Social support and healthrelated quality of life in women with breast cancer: a longitudinal study. Psycho- Oncology. 23: 1014-1020.

Lyubomirsky, S \& Kristin L. (2013). How do simple positive activities increase 
wellbeing?. Psychological Science, 22, 57-62.

IARC. (2012). Globocan 2012: Estimated Cancer Insidence, Mortality and Prevalence Worldwide in 2012. Diakses pada 26 Februari 2018

Moleong, L. J. (2016). Metodologi Penelitian Kualitatif. Bandung: PT Remaja Rosdakarya Offset.

Omidi A, Zargar F. (2014). Effect of mindfulness-based stress reduction on pain severity and mindful awareness in patients with tension headache: a randomized controlled clinical trial. Nurs Midwifery Stud. 3: e21136.

Park, C. L., Edmondson, D., Fenster, J. R. dkk. (2008). Meaning making and psychological adjustment following cancer: The mediating roles of growth, life meaning, and restored just-world beliefs. Journal of Consulting and Clinical Psychology, 76, 863-875.

Park, C. L. (2013) . Religion and meaning. In R. F. Paloutzian \& C. L. Park (Eds.), Handbook of the psychology of religion and spirituality, 2nd Ed. (pp. 257- 279) . New York: Guilford.

F. Paloutzian \& C. L. Park (Eds.), Handbook of the psychology of religion and spirituality, 2nd Ed. (pp. 257-279) . New York: Guilford.

Remmers H., Holtgräwe M., Pinkert. C. Stress and nursing care needs of women with breast cancer during primary treatment: a qualitative study. Eur J Oncol Nurs. 14: 11-16.

Sherman, A. C., Simonton, S., Latif, U. dkk. (2010). Seeking and found meaning:Associations with health outcomes among breast cancer survivors. Journals ofBehavioral Medicine, $39,170$.

Schmidt J. E., Andrykowski M. A. (2004). The role of social and dispositional variables associated with emotional processing in adjustment to breast cancer: an internet-based study. Health Psychol. 23: 259-266.

Smith, J. A., Flowers, P., \& Larkin, M. (2009). Interpretative Phenomenological Analysis: Theory, Method, and Research. Los Angeles, London, New Delhi, Singapore, Washington: SAGE Publications, Inc.

Steger, M., Frazier, P., Oishi, S., dkk. (2006). The meaning in life questionnaire: Assessing the presence of and search for meaning in life. Journal of Counseling Psychology, 53, 80-93

WHO. (2015). Cancer, Diakses pada tanggal 4 Februari 2018, http://www.who.int/mediacent re/facts heets / fs297/en/\#.

Winger, J. G., Adams, R.N., Mosher, C.E. (2016). Relations of meaning in life and sense of coherence to distress in cancer patients: a meta-analysis. Psychooncology. 25: 2-10 